\title{
Aspectos anatômicos do palato duro do primata Cebus apella (L. 1766)
}

\author{
Amanda Rocha Mortoza ${ }^{1}$ \\ Vanessa da Silva Ferreira ${ }^{1}$ \\ Polyana Alves Siqueira ${ }^{1}$ \\ Andréia Luciana Martins Ramos ${ }^{1}$ \\ Jussara Rocha Ferreira ${ }^{2 *}$ \\ ${ }^{1}$ Universidade Católica de Goiás, Goiânia, Brasil \\ ${ }^{2}$ Universidade de Brasília, Campus Universitário Darcy Ribeiro, Faculdade de Medicina \\ Área de Morfologia, Sala BC - 321, Asa Norte, CEP 70910-900, Brasília - DF, Brasil \\ *Autor para correspondência \\ jussararocha@unb.br
}

Submetido em 25/06/2007

Aceito para publicação em 02/11/2007

\section{Resumo}

Estudou-se quatorze palatos duros de primatas neotropicais (Cebus apella, L. 1766), fixados em formaldeído (10\%) conservados em álcool etílico $(70 \%)$ coletados dentro das normas internacionais de bioética. Os animais foram cedidos pela Faculdade de Medicina Veterinária e Zootecnia da Universidade de São Paulo em 1994. São provenientes do Zoológico de São Paulo e vieram a óbito por morte natural. Mediu-se em centímetros no vícero crânio (8 adultos e 6 jovens): comprimento do palato (CP), distâncias; interpremolares (DP), intermolares (DM), interorbitais (DO), altura da face média (FM). O palato apresentou cristas completas direitas $(7,64$ a 1,22$)$, esquerdas $(8,07$ a 1,71) e incompletas direitas $(1,71$ a 1,43$)$, esquerdas $(1,64$ a 1,3$)$. O diastema entre os dentes incisivos laterais marcou o início das cristas cuja terminação coincidiu com os segundos molares independente da maturidade do indivíduo. O palato é peculiar: ligeiramente côncavo indo da arcada dentária em direção a rafe mediana; revestido por mucosa despigmentada, com arcabouço ósseo composto pelas lâminas horizontais dos maxilares e palatinos; submucosa aderida ao periósteo e mucosa exibindo cristas palatinas relativamente proeminentes. As cristas apresentam-se como relevos rígidos da mucosa, ocorrendo variações nos antímeros, podendo-se inferir que quantitativamente o cumprimento do palato duro está fortemente correlacionado à maturidade do indivíduo, relativamente a distância interorbital, sendo que esta última guardou correlação com o comprimento do palato e a abertura da rima labial.

Unitermos: cristas palatinas, palato duro, Cebus apella, cavidade oral

\section{Abstract}

Anatomical aspect of the hard palate of the Cebus apella (Linnaeus, 1766) primates. Fourteen hard palates of neotropical primates were studied (Cebus apella), fixed on formaldehyde $(10 \%)$ and preserved in ethylic alcohol (70\%), collected according to the International Bioethics Committee. The animals were supplied by the Medicine College Veterinary Medicine and Zootecnica of the University of São Paulo in 1994. 
They originated from the São Paulo Zoo. They had died naturally. Measurement (in centimeters) of the viscerocranium ( 8 adults and 6 young animals) was made, including palatine length (PL), interpremolar distance (ID), intermolar distance (ID), interorbital distance (IDi), and midface height (MH). The palatine anatomy showed complete right crests (7.64 to 1.22), complete left crests (8.07 to 1.71), incomplete right crests (1.71 to 1.43), and incomplete left crests (1.64 to 1.3). The diasten between the lateral incisive teeth was the main anatomical landmark for the anterior end of the crest, and the landmark for the posterior end was the second molar teeth for all the specimens. The palate is very peculiar: mild concave, from the dental arcade to the median line, covered by the non-pigmented mucous tissue, with osseous structure composed of horizontal layers of the maxilar and palatine bones; sub mucous tissue attached to the periosteum and mucous tissue showing relatively prominent palatine crests. The crests appear as a rigid elevation of the mucous tissue, with some variations at the antimers. It may be concluded that the length of the hard palate is strongly related to the maturity of the animal, relative to the interorbital distance, and that the latter is also related to the length of the palate and the labial opening.

Key words: Palatine crests, hard palate, Cebus apella, oral cavity

\section{Introdução}

Os primatas do novo mundo têm sido estudados em muitos aspectos morfológicos (Castelli e Huelke, 1964; Zingeser, 1976; Feagle, 1999; Ferreira et al., 2000; Blumenchein e Ferreira, 2002; Ferreira et al., 2005) sendo que, algumas particularidades do sistema digestório especificamente em regiões faciais foram descritas por Geist, 1961; Molinare et al., 1994 a e b. Sabe-se, todavia, que as adaptações da cavidade oral dependem da dentição, da forma da cabeça, da projeção da língua, do hábito alimentar e da fonação (Hildebrand, 1995).

Embora tratadistas se refiram à morfologia do palato em primatas (Sicher e Dubrul, 1997; Moore e Dalley, 2001) o detalhamento das cristas palatinas não está completamente elucidado no animal que estudamos. Neste sentido o propósito deste trabalho foi descrever detalhes do palato duro e o comportamento das cristas palatinas nos dois antímeros. Para isto tomou-se como referência um estudo das pregas palatinas, feito em Bos indicus (Canellas et al., 1995) da raça nelore, no qual os palatos foram analisados a fresco. Nesta amostra descrevemos a anatomia do palato, que exibe pregas palatinas completas e incompletas em ambos os antímeros no macaco prego, Cebus apella Linnaeus, 1766.

Estudar os sistemas digestório, reprodutor e nervoso, entre outros aspectos, contribui com dados que permitam elucidar problemas de alimentação, perpetuação das espécies naturais e comportamento animal. No atual estado da ciência é importante deter conhecimento sobre os animais silvestres da biodiversidade tropical seja para sua preservação, seja para a proteção de seu fluxo gênico visando a potencial capacidade de usar esta fauna como modelo biológico ou para potencial exploração zootécnica.

\section{Material e Métodos}

Este trabalho é descritivo quantitativo onde, estudou-se a morfologia do palato duro de quatorze Cebus apella (machos: seis jovens e oito adultos) com ênfase nas estrias palatinas. Os animais doados para pesquisa, provenientes do Zoológico de São Paulo (tendo óbito por morte natural), foram coletados de acordo com as regras da Comissão de Ética da Faculdade de Medicina Veterinária Zootecnia da Universidade de São Paulo (FMVZ/ USP). Tendo sido doados para esta e outras pesquisas do grupo em 1994. Para fins de análise do palato nos 28 antímeros utilizamos parcialmente o critério de Canellas et al. (1995), tomando as seguintes medidas no víscero crânio: comprimento do palato duro (CP), desde a papila incisiva até a margem caudal do palato duro; abertura da rima labial (RL), partindo do ângulo labial esquerdo até o direito; distância intermolares (DM), tomada entre os segundos dentes molares nos animais jovens e entre os terceiros nos adultos; distância interorbital (DO), medida tomada entre as margens mediais das órbitas direita e esquerda e altura da fase média (FM), tomada entre o plano naso-labial até a crista frontal; quantificamos as cristas palatinas nos dois antímero registrando, por animal, o número de cristas completas e incompletas. As denominações das estruturas obedeceram ao International Committee 
on Veterinary Gross Anatomical Nomenclature (1994) com base nas ilustrações de Schaller (1999), nas estruturas que foram possíveis estabelecer analogias.

Os parâmetros foram aferidos em centímetros através de paquímetro de precisão (FIMEC, Rostfru ger' artet). Para fins de análise quantitativa utilizamos o software SPSS. O software foi obtido em versão reduzida e gratuita (www.spss.com/download - SPSS 15,0 for Windows - $164 \mathrm{MB}$ ), ilustrando os resultados em gráficos (histogramas) e tabelas.

As variações das cristas palatinas completas e incompletas nos dois antímeros, e as correlações das variáveis (supracitadas) com as quais trabalhamos permitiram-nos analisar e discutir os dados.

\section{Resultados e Discussão}

O estudo de 28 antímeros do palato duro de Cebus apella possibilitou-nos compreender o padrão da anatomia das cristas palatinas, nestes animais. $\mathrm{O}$ palato apresentou-se ligeiramente côncavo no sentido da arcada dentária em direção medial a rafe mediana da língua, revestido por mucosa sem pigmentação. No palato foram observadas: a papila incisiva, a rafe palatina e as cristas transversais. A rafe palatina iniciava-se caudalmente à papila incisiva entre o primeiro par de cristas e seguia no sentido dorso caudal entre estas como um raso sulco mediano entre as duas metades do palato, terminando na borda aboral da margem caudal deste. Esta topografia difere da apontada por Moore e Dalley (2001), Madeira (2001) e Sicher e Dubrul (1997) em primatas humanos na medida em que estes autores não se referiram à rafe palatina tão bem delineada como a encontramos neste primata do presente estudo.

Em gorilas (Gorilla gorilla), orangotangos (Pongo pygmaeus) e bugio (Alonatta seniculus) (Raven, 1950; Schön, 1964; Winker, 1991) os dados morfológicos do aspecto do palato são inexistentes para comparação com os achados em Cebus apella.

As cristas palatinas se tornavam mais salientes na mucosa e eram coincidentes com a linha dos dentes caninos. Originavam-se na rafe palatina e dirigiam-se às margens gengivais laterais do palato duro. Quando completas, eram relativamente alinhadas no sentido transversal e assumiam inflexões caudais. Se incompletas, ocorria, conseqüentemente, maior assimetria entre os antímeros. As cristas são representações de relevos rígidos da mucosa que determinam entre a rafe palatina e as margens laterais do palato duro dois planos de inclinação caudal, que terminaram na margem caudal do palato duro. Esta topografia encontrada possivelmente favorece o trânsito do alimento em direção a faringe como sugerido em outros mamíferos por Barone (1956) Warwich e Willians (1979). O primeiro par de cristas palatinas completas $(100 \%)$ terminava lateralmente ao diastema entre os dentes incisivos laterais e os caninos, semelhante a outros estudos em mamíferos feitos por Barone (1956) Canellas et al. (1995). As figuras 1 e 2 revelaram a distribuição das cristas completas e incompletas nos dois antímeros.

Nos histogramas (Figuras 1 e 2) estão expressos o número de cristas palatinas por indivíduo, que variou de 7 a 14. Nas 28 observações puderam ser notadas de 5 a 9 cristas completas e 0 a 4 incompletas à direita contra 6 a 10 cristas completas e 0 a 4 incompletas a esquerda. Na tabela 1 estão expressos os cálculos médios por antímero demonstrando que ocorreram significativos desvios padrões e variâncias, possivelmente em função do tamanho da amostra. Canellas et al. (1995) observaram, em bovinos, que a variação do número de cristas palatinas entre os antímeros não teve significativo desvio.

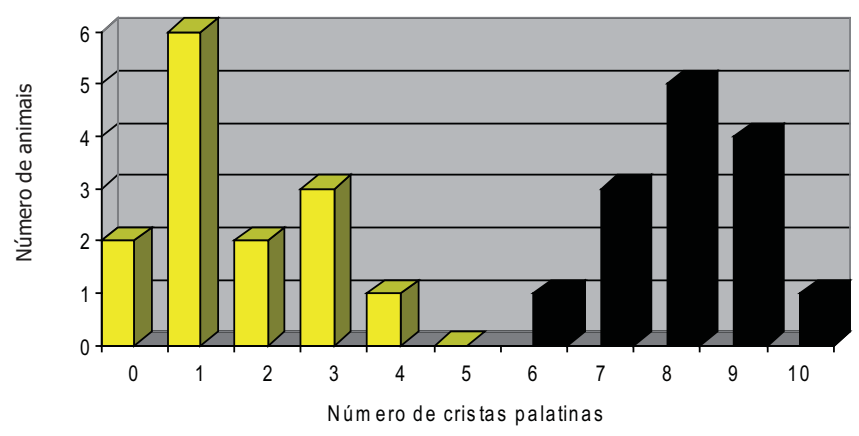

$\square$ Cristas incompletas à esquerda

- Cristas completas à esquerda

FIGURA 1: Número de cristas palatinas completas e incompletas no antímero esquerdo do palato duro, na cavidade oral do primata Cebus apella, L. 1766, em função da amostra. Fonte: dados de pesquisa, FM/UnB/2005/2007. 


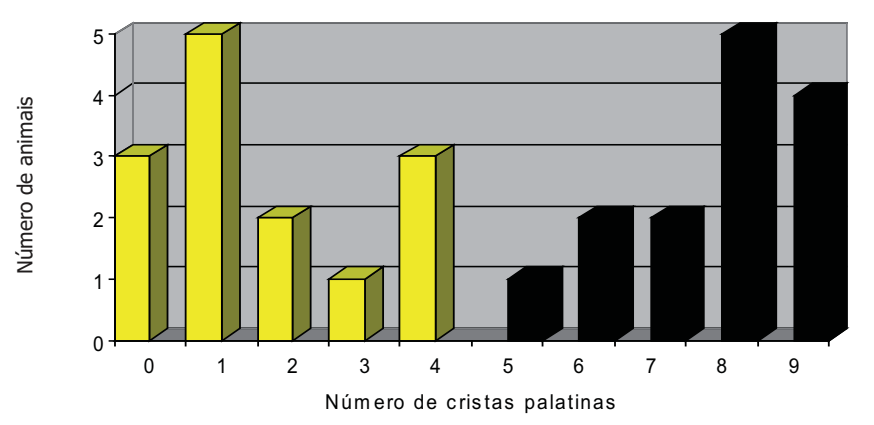

$\square$ Cristas incompletas à direita

- Cristas completas à direita

FIGURA 2: Número de cristas palatinas completas e incompletas no antímero direito do palato duro, na cavidade oral do primata Cebus apella, L. 1766, em função da amostra. Fonte: dados de pesquisa, FM/UnB/2005/2007

TABELA 1: Cálculo das médias aritméticas $(X)$, variância $(\mathrm{V})$, desvios padrão $(\mathrm{S})$, do número de cristas palatinas completas a direita (CD), incompletas a direita (ID), e do total de cristas à direita (TD); do número de cristas palatinas completas a esquerda (CE), incompletas a esquerdas (IE), e do total de cristas à esquerda (TE) em função da amostra analisada, no palato duro de Cebus apella (L. 1766).

\begin{tabular}{lccccccc}
\hline \multirow{2}{*}{ AMOSTRA } & \multicolumn{6}{c}{ VARIÁ VEIS ANALISADAS (mm) } \\
\cline { 2 - 8 } & & CD & ID & TD & CE & IE & TE \\
\cline { 2 - 8 } 14 palatos & $\mathrm{X}$ & 7,64 & 1,71 & 9,36 & 8,07 & 1,64 & 9,71 \\
duros & $\mathrm{V}$ & 1,63 & 2,22 & 1,48 & 1,15 & 1,48 & 2,53 \\
& $\mathrm{~S}$ & 1,28 & 1,49 & 1,22 & 1,07 & 1,22 & 1,59 \\
\hline
\end{tabular}

Fonte: dados de pesquisa. FM/UnB/2005/2007.

A mucosa encontrava-se fortemente fixada ao osso, semelhante aos achados de Warwick e Willians (1979) Llorca (1952). O palato duro apresentou um arcabouço composto pelos ossos maxilar e palatino (lâminas horizontais), com topografia da mucosa das cristas diferente dos primatas humanos e prossímios, classe última tratada por Schultz (1960) que se referiu a 7 ou 8 pares de cristas palatinas, na maioria dos gêneros, em arranjos simétricos voltadas para a margem caudal do palato duro. Em primatas humanos Llorca (1952) referiu-se ao palato duro como sendo o esqueleto que forma as porções horizontais do osso maxilar e do palatino, sendo a submucosa aderida ao periósteo e a mucosa exibindo pregas palatinas transversais. Por sua vez Warwick e Willians (1979) relataram a presen- ça de mucosa espessa, pálida, enrugada, recoberta por epitélio escamoso estratificado, enquanto Alves (1962) descreveu no palato duro as seguintes camadas: mucosa rosada aderente ao osso, camada glandular representada pelas glândulas, salivares e palatinas e camada óssea. A mucosa foi denominada "túnica mucosa mastigatória" por Johnson e Moore (1999) e os autores sinalizam que sua estrutura é composta por "epitélio paraqueratinizado". No presente trabalho em Cebus apella estes aspectos não foram averiguados para comparações pertinentes.

Em Platyrrhines há relato (Schultz, 1960) de 5 a 11 cristas contra 5 a 6 na família Callithricidae. Na família Cebidae este mesmo estudo referiu-se às cristas assimétricas e irregulares no Cebus e Saimiri. Condição oposta aos Cebídeos que analisamos cujos arranjos apresentaram-se simétricos e relativamente regulares independente da presença de cristas completas ou incompletas (Figura 1 - A, B, C, D). Comparado este estudo ao do autor supracitado, pode-se inferir que os palatos dos primatas por ele descritos assemelham-se aos animais adultos desta amostra, cujas ilustrações exibem cristas completas e incompletas em Atelles geoffroyi e Pan troglodyte e em humanos.

A análise do arranjo das cristas palatinas deste estudo em relação às de outros autores (Testut e Jacob, 1952; Schultz, 1960), indicou haver uma relativa semelhança em relação aos modelos dos palatos duros dos animais adultos desta amostra. Concordamos que a distribuição topográfica panorâmica das cristas palatinas no Cebus apella, quando analisamos o palato em conjunto seja relativamente parecida (Figura 3 - A, $\mathrm{B}, \mathrm{C}, \mathrm{D})$ entre os indivíduos observados mesmo sendo estes de maturidade diferente. No entanto ocorreu variação entre os antímeros, que contemplaram cristas completas e incompletas em direções transversais e ligeiramente oblíquas, relativamente a rafe palatina, conforme apontaram Testut e Jacob, (1952) em humanos, achados semelhantes foram relatados em outros primatas; Pan paniscus, Tarsius, Aotes, Alouatta, Papio, Erythrocebus, Presbytis, Hylobates, Sympholangus, Pongo, Pan, Gorilla e Homo (Schultz, 1960; Feagle, 1999). 


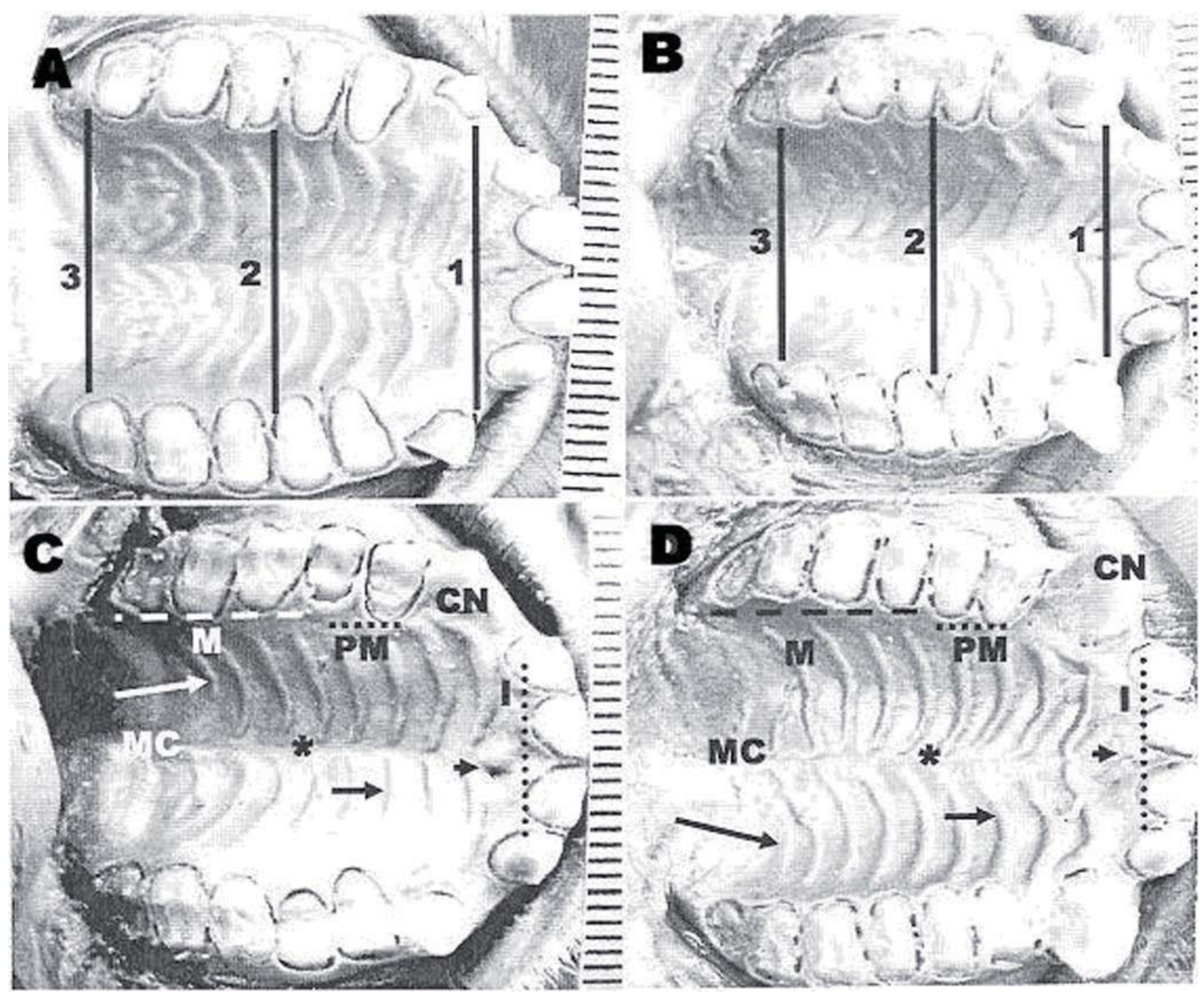

FIGURA 3: Fotografia de palato duro de primata (Cebus apella, L. 1766), animais jovens (A e C) e adultos (B e D) nas quais destacam-se linhas e pontos de medição: linha de união entre os diastemas (1), distância entre os dentes pré-molares (2), distância entre os dentes molares (3). Estão ressaltados os elementos anatômicos: papila incisiva (cabeça de seta), crista completa (seta curta), crista incompleta (seta longa), rafe palatina (asterisco), margem caudal do palato duro (MC), dente incisivo superior (I), dente canino $(\mathrm{CN})$, dente pré-molar (PM) e dente molar $(\mathrm{M})$.

$\mathrm{O}$ aspecto geral do palato, independente da idade (Figura 3: BD palato adulto; AC, palato jovem), deixou claro que em relação ao tamanho da cabeça, o comprimento do palato e as outras variáveis analisadas (Tabela 2), não interferiram diretamente na topografia da mucosa palatina. As cristas destacaram-se como impressões (relevos) da mucosa que se apresentaram independentemente: do número de dentes eruptados ou do estagio de erupção destes; das distâncias: intermolares e interpremolares, da distância entre os diastemas e da altura da face média.
Na tabela 2 estão expressas medidas quantitativas que utilizamos buscando averiguar se o fato de termos analisado crânios de indivíduos adultos e de jovens, interferiu nos resultados. Aplicado o teste de correlação no programa estatístico, software SPSS, percebemos que a altura da face média não interferiu nos resultados. A distância interorbital guardou co-relação com o comprimento do palato e a abertura da rima labial. Por sua vez as distâncias interpremolares e intermolares correlacionaram-se entre si, e a maturidade do indivíduo está relativamente correlacionada à distância interorbital e 
fortemente correlacionada ao comprimento do palato. Embora apenas Canellas et al. (1995) tenham analisado aspectos semelhantes em Bós indicus consideramos não poder transferir as conclusões para o Cebus apella $e$ vice-versa uma vez que, o palato destas espécies, dentição e a forma da cabeça e particularmente seus víscero-crânio são significativamente diferentes. Há que se levar em conta a consideração do zoólogo (Hildebrand, 1995) que interpreta que desenhos anatômicos de cavidades dependeriam, no exercício de suas funções, de aspectos multifatoriais, dentre estes, o habito alimentar e a vocalização.

TABELA 2: Cálculo das médias aritméticas (X), variância $(\mathrm{V})$ e desvios padrão $(\mathrm{S})$ das variáveis: altura da face média $(\mathrm{FM})$, distância interorbital (DO) comprimento do palato $(\mathrm{CP})$, abertura da rima labial $(\mathrm{RL})$, distância interpremolar (DP), e distância intermolar (DM) de acordo com o total da amostra, no palato duro de Cebus apella (L. 1766).

\begin{tabular}{lccccccc}
\hline \multirow{2}{*}{ AMOSTRA A } & \multicolumn{6}{c}{ VARIÁVEIS ANALISADAS (mm) } \\
\cline { 2 - 8 } & & FM & DO & CP & RL & DP & DM \\
\hline \multirow{2}{*}{$\begin{array}{l}\text { 14 palatos } \\
\text { duros }\end{array}$} & X & 2,33 & 4,89 & 2,91 & 5,04 & 1,97 & 2,17 \\
\cline { 2 - 8 } & $\mathrm{V}$ & 0,13 & 0,37 & 0,22 & 0,22 & 0,06 & 0,09 \\
\cline { 2 - 8 } & $\mathrm{S}$ & 0,36 & 0,61 & 0,47 & 0,47 & 0,25 & 0,32 \\
\hline
\end{tabular}

Fonte: dados de pesquisa. FM/UnB/2005/2007.

Na tabela 3 estão expressos o número das cristas palatinas, por antímero e suas respectivas freqüências absoluta e relativa. Os dados refletem uma alteração do número de cristas palatinas por indivíduo. Na análise da figura 3, o padrão do relevo da mucosa do palato, visto como um todo, é relativamente semelhante nos diferentes indivíduos de diversas faixas etárias.

Ao cruzarmos os dados do número total de cristas por antímero demonstrou-se que 70,5\% dos espécimes analisados tinham entre 18 ou 21 cristas palatinas. Afastaram-se relativamente pouco da faixa de maior ocorrência quatro animais, sendo estes, dois jovens; o primeiro com 14 e o segundo com 16 cristas, e dois adultos; o primeiro com 17 e o segundo com 26 cristas palatinas representando respectivamente $7,1 \%$ do total da amostra. Quando ocorreu assimetria entre os antímeros, em função do número de cristas, o número a maior aconteceu sempre à esquerda independente da completude ou não da crista considerada (Figura 3).

TABELA 3: Número de cristas palatinas, no palato duro, da cavidade oral do primata Cebus apella (L. 1766) e freqüências absoluta e relativa correlacionadas entre os antímeros direito $(\mathrm{AD})$ e esquerdo $(\mathrm{AE})$.

\begin{tabular}{|c|c|c|c|c|c|c|c|c|}
\hline \multirow{2}{*}{$\begin{array}{l}\text { Freqüências: } \\
\text { absoluta (fa), } \\
\text { relativa (\%). }\end{array}$} & \multicolumn{7}{|c|}{ Número de cristas palatinas por antímeros } & \multirow[b]{2}{*}{ Total } \\
\hline & $\mathrm{AD}$ & 7 & 8 & 9 & 10 & 11 & 14 & \\
\hline (fa) & \multirow[b]{2}{*}{7} & 1,0 & - & - & - & - & - & 1,0 \\
\hline$(\%)$ & & 7,1 & - & - & - & - & - & 7,1 \\
\hline (fa) & \multirow[t]{2}{*}{8} & - & 1,0 & 1,0 & - & - & - & 2,0 \\
\hline$(\%)$ & & - & 7,1 & 7,1 & - & - & - & 14,3 \\
\hline (fa) & \multirow[t]{2}{*}{9} & - & - & 3,0 & 1,0 & - & - & 4,0 \\
\hline$(\%)$ & & - & - & 21,4 & 7,1 & - & - & 28,6 \\
\hline (fa) & \multirow{2}{*}{10} & - & - & - & 5,0 & 1,0 & - & 6,0 \\
\hline$(\%)$ & & - & - & - & 35,7 & 7,1 & - & 42,9 \\
\hline (fa) & \multirow{2}{*}{12} & - & - & - & - & - & 1,0 & 1,0 \\
\hline$(\%)$ & & - & - & - & - & - & 7,1 & 7,1 \\
\hline \multirow{2}{*}{ Total } & & 1,0 & 1,0 & 4,0 & 6,0 & 1,0 & 1,0 & 14,0 \\
\hline & & 7,1 & 7,1 & 28,6 & 42,9 & 7,1 & 7,1 & 100,0 \\
\hline
\end{tabular}

Fonte: dados de pesquisa. FM/UnB/2005/2007.

Consideramos poder concluir que as partes duras componentes do palato duro do primata Cebus apella estão representadas pelas lâminas ósseas horizontais dos ossos maxila e palatino. A submucosa é aderida ao periósteo e a mucosa exibe cristas palatinas relativamente proeminentes. As cristas apresentam-se como relevos que refletem um padrão individual característico (único). Há variações nos antímeros em relação ao número de cristas palatinas completas e incompletas, podendo-se inferir que quantitativamente o cumprimento do palato duro está fortemente correlacionado à maturidade do indivíduo, relativamente à distancia interorbital, sendo que esta última guardou correlação com o comprimento do palato e a abertura da rima labial.

\section{Referências}

Alves, E. 1962. Anatomia descritiva da boca. $3^{\text {a }}$ parte. In: Alves, E. (ed.). Anatomia odontológica. Livraria Atheneu S.A., Rio de Janeiro, Brasil, p.274-275.

Barone, R. 1956. Anatomia comparata dei mammiferi domestici. V. Terzo Milano. Edagricole, Itália, 537pp. 
Blumenchein, A. R.; Ferreira, J. R. 2002. Anatomic study of the neotropic primate's submandibular gland ducts (Cebus apella Linnaeus, 1766). Revista Chilena de Anatomia, 20 (1): 55-61.

Canellas, L. F. L.; Souza, W. M.; Miglino, M. A.; Perri, S. H. V. 1995. Características anatômicas das pregas palatinas transversais em bovinos da raça nelore. Revista UNIMAR, 17 (2): 281-290.

Castelli, W. A.; Huelke, D. F. 1964. The arterial system of the head and neck of the rhesus monkey with emphasis on the external carotid system. American Journal of Anatomy, 116 (1): 149-170.

Feagle, J. G. 1999. The primate body. In: Feagle, J. G. (Ed.). Primate adaptation and evolution. $2^{\text {nd }}$ ed. Academic Press, San Diego, USA, p.14-17.

Ferreira, J. R.; Blumenchein, A. R.; Oliveira, A. B. S.2000. Estudo anatômico do modelo arterial de vasos responsáveis pelo aporte sanguíneo da glândula submandibular de primatas neotropicais (Cebus apella Linnaeus, 1766). Acta Scientiarum, 22 (2): 573-579.

Ferreira, J. R.; Pinto Júnior, N.; Kajita, D.; Cirqueira, D. S.; Nogueira, D. J. 2005. Estudo da anatomia descritiva e topográfica do músculo digástrico em primatas (Cebus apella Linnaeus, 1766). Brazilian Journal of Veterinary Research and Animal Sciences, 42 (2): 113-121.

Geist, F. D. 1961. Nasal cavity, larynx, mouth and pharynx. In: Linebak, P. (Ed.). The anatomy of the rhesus monkey (Macaca mulatta). Hafner, New York, USA, p.329-330.

Hildebrand, M. 1995. Análise da estrutura dos vertebrados. Atheneu, São Paulo, Brasil, 700pp.

International Committee on Veterinary Gross Anatomical Nomenclature. 1994. Nômina anatômica veterinária. 4. ed. Zurich and Ithaca, New York, USA, 614pp.

Johnson, D. R. Moore, W. J. 1999. Anatomia para estudantes de odontologia. 3. ed. Guanabara Koogan, Rio de Janeiro, Brasil, 396pp.

Llorca, F. O. 1952. Intestino cefálico. In: Llorca, F. O. (Ed.). Anatomia humana. Tomo Tercero. Editorial Científico Médica, Barcelona, Espanha, p.351-353.

Madeira, M. C. 2001. Boca. In: Madeira, M. C. (Ed.). Anatomia da face: bases anatomo funcionais para a prática odontológica. 3. ed. Sarvier, São Paulo, Brasil, p.80-82.
Molinari, S. L.; Miranda Neto, M. H.; Madeira, M. C. 1994a. Número e localização dos forames mentais do macaco de cheiro (Saimiri sciureus - Linnaeus, 1758). Revista UNIMAR, 16 (2): 427-435.

Molinari, S. L.; Navarro, J. A. C.; Toledo Filho, J. C.; Costa, P. F.; Miranda Neto, M. H. 1994b. Systematization of the branching of the inferior alveolar nerve in the squirrel monkey mandible (Saimiri sciureus). Revista Brasileira de Ciências Morfológicas, 11 (2): $57-60$.

Moore, K. L.; Dalley, A. F. 2001. Cabeça. In: Moore, K. L. \& Dalley, A. F. (eds). Anatomia orientada para a clínica. 4. ed. Guanabara Koogan, Rio de Janeiro, Brasil, p.836-837.

Raven, H. C. 1950. The anatomy of the gorilla. Columbia, University Press. New York. 347 pp.

Schaller, O. 1999. Nomenclatura anatômica veterinária ilustrada. Manole, São Paulo, Brasil, 614pp.

Schön, M. A. 1964. Possible function of some pharyngeal and lingual muscles of the howling monkey (Alouatta seniculus). Acta Anatomica, 58 (1): 271-283.

Schultz, A. H. D. 1960. Palatine ridges. In: Hofer, H.; Schultz, A. H. \& Starck, D. (Ed.). Primatologia handbuch der primatenkunde. III, Teil 2. S. Karges Ag., Basel, Suiça, p.127-138

Sicher, H.; Dubrul, L. L. 1997. Anatomia bucal. 6. ed. Guanabara Koogan, Rio de Janeiro, Brasil, 296pp.

Testut, L.; Jacob, O. 1952. Cara. In: Testut, L. \& Jacob, O. (Ed.). Tratado de anatomía topográfica con aplicaciones médicoquírúrgicas. 8. ed. Tomo primero. Salvat Editores S.A., Barcelona, Espanha, p.277-285.

Warwick, R.; Willians, P. L. 1979. Esplancnologia. In: Warwick, R. \& Willians, P. L. (Ed.). Gray Anatomia. Tomo II. 35. ed. Guanabara Koogan, Rio de Janeiro, Brasil, p.1137-1140.

Winker, L. A. 1991. Morphalogy and variability of masticatory structures in the orangutan. International Journal of Primatology, 12 (1): 45-65.

Zingeser, M. R. 1976. Arch form, tooth size, and occlusomandibular kinesis in the Ceboidea. American Journal of Physical Antropologists, 45 (2): 317-330. 